\title{
High-resolution maps of the characteristic energy of precipitating auroral particles
}

\author{
M. J. Kosch \\ Max-Planck-Institut für Aeronomie, Katlenburg-Lindau, Germany \\ Department of Communication Systems, Lancaster University, Lancaster, England, U.K. \\ F. Honary, C. F. del Pozo, and S. R. Marple \\ Department of Communication Systems, Lancaster University, Lancaster, England, U.K. \\ T. Hagfors \\ Max-Planck-Institut für Aeronomie, Katlenburg-Lindau, Germany
}

\begin{abstract}
For the first time we produce high-resolution maps of the characteristic energy of precipitating electrons from ground-based instrumentation in the auroral zone over northern Scandinavia. This is done by combining intensity-calibrated optical data at 557.7 $\mathrm{nm}$ from the Digital All-Sky Imager (DASI) with auroral absorption images from the Imaging Riometer for Ionospheric Studies (IRIS). Energy maps are produced with high temporal $(10 \mathrm{~s})$ and spatial $(10 \mathrm{~km})$ resolution within a common geographic area of $240 \times$ $240 \mathrm{~km}$. Both IRIS and DASI have the European Incoherent Scatter (EISCAT) radar within their common field of view. EISCAT is capable of making accurate measurements of the electron density height profile which, with the assistance of an atmospheric model, are inverted into equivalent energy spectra of the flux of precipitating electrons. However, incoherent scatter radars generally have a very small field of view $\left(<1^{\circ}\right)$, making studies of the energy spectrum of the precipitating particles over a wide field of view impractical. Since IRIS and DASI are sensitive to high- and medium-energy electrons, respectively, EISCAT data are used to calibrate the characteristic energy of the precipitating particles for an assumed energy spectrum against a combination of IRIS and DASI data. This empirical calibration is then used throughout the common field of view of IRIS and DASI. An initial study illustrates the spatial relationship between the different energy ranges during a substorm onset and illustrates a new way to interpret auroral phenomena.
\end{abstract}

\section{Introduction}

Auroral precipitation processes have been extensively studied using optical imagers and riometers and more recently imaging riometers [e.g., Stauning, 1996a]. It has been long known that some relationship between the optical aurora and ionospheric absorption exists [e.g., Ansari, 1964; Campbell and Leinbach, 1961]. Observations of auroral optical emissions and absorption give the spatial and temporal distribution of softer $(<15 \mathrm{keV})$ [e.g., Burch, 1991; Belon et al., 1966] and harder (>25 keV) [e.g., Penman et al., 1979; Collis et al., 1984] precipitating particles, respectively. The magnitude of the optical emissions and auroral absorption relate to the flux of precipitating particles within the corresponding energy band. It has been amply demonstrated that there is a relationship between the energy and flux of precipitating particles, which cause ionization, and various auroral optical emissions [e.g., Robinson and Vondrak, 1994; Mende et al., 1984; Vondrak et al., 1983; Sears and Vondrak, 1981; Vondrak and Sears, 1978]. However, all these studies were done with narrow fields of view, and there have been no attempts to study the small-scale spatial and temporal morphology of the particle energies over a wide field of view.

Copyright 2001 by the American Geophysical Union.

Paper number 2001JA900107.

0148-0227/01/2001JA900107\$09.00
It is possible to infer the energy spectrum of precipitating electrons by inverting the electron density altitude profile obtained from incoherent scatter radars [e.g., Kirkwood and Osepian, 1995; del Pozo et al., 1997]. However, such radars generally have a very small field of view $\left(<1^{\circ}\right)$. Scanning the radar in order to expand the effective field of view is not useful as the slow moving antennae severely limit the temporal resolution achievable. Assuming one wishes to make a $24 \times 24$ grid scan of the sky, even if the radar only spends $10 \mathrm{~s}$ at each position, including antenna moving time, it would still take 96 min to complete one scan. For auroral studies such a temporal resolution is wholly inadequate when phenomena are known to occur on timescales of less than a minute.

The flux and energy of precipitating electrons can be obtained from satellite observations [e.g., Ishimoto et al., 1988; Rees et al., 1988], and global maps of these parameters have been produced [e.g., Hardy et al., 1985; Spiro et al., 1982]. Although these plots have a very large coverage, they are statistical averages of many satellite passes, which are unsuitable for case studies. Empirical relationships between absorption magnitude and the flux of high-energy particles measured by geostationary satellites have been found [e.g., Collis et al., 1984; Penman et al., 1979]. However, satellite data do not have the spatial resolution in the ionosphere required for detailed studies of the spatial morphology of the precipitating particle energies, which is possible from the ground. 
In this paper a technique is developed to spatially expand the point measurement made by an incoherent scatter radar using a combination of two imaging instruments, i.e., an all-sky imager and an imaging riometer. Auroral optical emissions and absorption are observed in the $E$ region above $100 \mathrm{~km}$ and in the $D$ region below $95 \mathrm{~km}$ altitude, respectively, corresponding to two different parts of the energy spectrum, $<15 \mathrm{keV}$ for aurora and $>25 \mathrm{keV}$ for absorption [Rees, 1963; Bailey, 1968; del Pozo et al., 1997]. Assuming that the higher- and lowerenergy components come from the same source particle population, and assuming that the energy spectrum of the precipitating particles can be described by a mathematical function containing only two unknown variables, the two observables (auroral intensity and absorption magnitude) can be related to a single characteristic descriptor of the assumed energy spectral function. Once this empirical relationship is found, the characteristic descriptor of the energy spectrum can be computed for any part of the sky where the aurora and the absorption are quantitatively measured simultaneously.

\section{Theory}

The continuity equation for $E$ region electron densities $\left(N_{e}\right)$ measured at a given altitude is given by [Brekke et al., 1989]

$$
\frac{d N_{e}}{d t}=Q_{p}+Q_{s}-\alpha N_{e}^{2}-\operatorname{div}\left(N_{e} \cdot \bar{\nu}\right)
$$

where $Q_{p}$ is the ion production rate due to auroral precipitation, $Q_{s}$ is the ion production rate due to solar radiation, $\alpha$ is the height-dependent effective recombination coefficient, $\bar{\nu}$ is the electron bulk velocity, and $t$ is time. Assuming it is nighttime (i.e., $Q_{s}=0$ ), steady state conditions prevail (i.e., $d N_{e} /$ $d t=0)$, and that the transport term $\operatorname{div}\left(N_{e} \cdot \bar{\nu}\right)$ becomes negligible at $D$ and lower $E$ region altitudes when compared to $\alpha N_{e}^{2}$ [Brekke et al., 1989], (1) simply becomes

$$
\alpha N_{e}^{2}=Q_{p} .
$$

Auroral particles bombarding the atmosphere will lose energy at the rate of $\sim 35 \mathrm{eV}$ per ion pair formed [Rees and Luckey, 1974]. Upon recombination, only a small fraction $(\sim 4 \%)$ of the energy thus deposited results in spectroscopic emissions observable from the ground [Rees and Luckey, 1974]. However, for a given precipitation rate by particles of a certain energy, it is reasonable to expect the production of auroral photons to remain constant. To first order, we can assume that auroral optical intensity $I$ is proportional to $Q_{p}$. Hence, for $E$ region electron density variations associated with particle precipitation, we have

$$
N_{e} \propto \sqrt{I},
$$

where $\sqrt{I}$ is a measure of the particle flux which generates the nighttime $E$ region electron density. Total absorption $A$ integrated over the entire path $L$ is given by [Hargreaves, 1969]

$$
A=4.6 \times 10^{-5} \int_{0}^{\infty} \frac{N_{e} \nu}{\nu^{2}+\left(\omega \pm \omega_{L}\right)^{2}} d L(\mathrm{~dB}),
$$

where $N_{e}$ is the total electron density, $\nu$ is the electron collision frequency, $\omega$ is the observation frequency, $\omega_{L}=\omega_{H} \cos \theta, \omega_{H}$ is the gyrofrequency, $\theta$ is the angle between the magnetic field and propagation direction, and \pm implies the extraordinary $(-)$ and ordinary $(+)$ wave, respectively. By subtracting the quiet day curves from the riometer data [Browne et al., 1995], it is possible to determine the absorption primarily due to particle precipitation only. Theoretical calculations show that absorption is directly related to the flux of incident electrons, with higher energies producing more absorption [Bailey, 1968]. In the auroral zone, $D$ region absorption dominates. To first order, (4) reduces to

$$
A(\mathrm{~dB}) \propto N_{e}
$$

in the $D$ layer. Hence absorption is a measure of the particle flux which generates the nighttime $D$ region electron density. del Pozo et al. [1997] have found that the effective deposition altitude for precipitating electrons can be related to their energy by

$$
E(H)=4 \times 10^{5} e^{-0.101 H}(\mathrm{keV}),
$$

where $H$ is altitude in kilometers. The primary influx of particle energy into the auroral atmosphere is carried by electrons with energies between 1 and $10 \mathrm{keV}$ [Burch, 1991]. Optical aurora normally occurs above $100 \mathrm{~km}$ altitude [Currie, 1955; Störmer, 1955], resulting from precipitating electrons with energies $E<15 \mathrm{keV}$ [Rees, 1963; del Pozo et al., 1997]. For example, $E \approx 10 \mathrm{keV}$ implies an altitude of $H \approx 105 \mathrm{~km}$ in the $E$ region. Riometer absorption normally occurs below 95 $\mathrm{km}$ [Penman et al., 1979], resulting from precipitating electrons with energies $E>25 \mathrm{keV}$ [Rees, 1963; del Pozo et al., 1997]. For example, $E \approx 47 \mathrm{keV}$ implies an altitude of $H \approx 90 \mathrm{~km}$ in the $D$ region.

Many early observations with single-beam riometers and photometers have established that fluctuations in auroral optical intensity are correlated to variations in absorption magnitude [e.g., Ansari, 1964; Campbell and Leinbach, 1961; Eather and Jacka, 1966; Gustafsson, 1964, 1969; Holt and Omholt, 1962], although Barcus [1965] also found evidence of uncorrelated behavior. Stoker et al. [1996] found a similar correlation for the central narrow beams of an imaging riometer and the corresponding regions in auroral all-sky images, although the best correlation occurred for spatially adjacent regions. According to Rees [1963], ion production $Q_{p}$ is linearly related to the flux of precipitating particles $(F)$, whereas ion production is proportional to the square of the resulting electron density (see equation (2)). Assuming that the hard and soft energy components of the electron precipitation are from the same source population, and that the energy distribution remains constant, then

$$
\frac{A}{\sqrt{I}} \propto \frac{N_{e}(H<96 \mathrm{~km})}{N_{e}(H>101 \mathrm{~km})} \propto \frac{\sqrt{F(E>25 \mathrm{keV})}}{\sqrt{F(E<15 \mathrm{keV})}} .
$$

Equation (7) implies

$$
E \propto \frac{A}{\sqrt{I}},
$$

where $A / \sqrt{I}$ is independent of flux. The ratio of absorption to square root of optical intensity is an energy indicator for the precipitating electrons. Theoretical analysis shows the energy indicator to be quasilinearly dependent on energy [Johansen, 1965a; Bailey, 1968]. Experiments using photometers and single-beam riometers seem to confirm this [Eather and Jacka, 1966]; however, the empirical relationship may be different for individual cases [Johansen, 1965b]. A major problem with the early work was that the single-beam riometers generally have a 
greater field of view $\left(>15^{\circ}\right)$ compared to photometers $\left(<10^{\circ}\right)$. Using a single-beam riometer and photometer at $557.7 \mathrm{~nm}$, Berkey [1968] and Gustafsson [1969] used the energy indicator to infer changes of the incident flux spectrum; however, they lacked any means to calibrate these measurements into units of energy.

An energy distribution function of the form

$$
F(E)=k E^{\gamma} e^{-E / E_{0}}
$$

has been found to represent closely many observed primary auroral flux spectra [Rees, 1989], where $F$ is flux, $k$ is a constant of proportionality, $E$ is energy, and $E_{0}$ is the characteristic energy. For $\gamma=0$ an exponential function is obtained, and for $\gamma=1$ a Maxwellian distribution is obtained. Satellite [e.g., Lui et al., 1977; Hardy et al., 1985] and rocket [e.g., Ogilvie, 1968; Westerlund, 1969; Arnoldy et al., 1974; Lundin, 1976; Maynard et al., 1977] measurements indicate that the energy spectrum of electrons incident on the atmosphere can be reasonably described by a Maxwellian distribution, or by an exponential function if the low-energy part of the spectrum (typically $<1$ $\mathrm{keV}$ ) is ignored. However, such spectral functions are not always good fits [e.g., Evans, 1968; Whalen and McDiarmid, 1972].

In this study we test both functional forms of (9). Assuming the hard and soft electron precipitation is from the same source population and that the energy spectral shape remains constant, we define for the Maxwellian distribution $(\gamma=1)$

$$
F(E)_{I}=k_{I} E_{I} e^{-E_{I} / E_{0}} \propto \sqrt{I},
$$

for optical aurora $I$ from the derivation of (3), and

$$
F(E)_{A}=k_{A} E_{A} e^{-E_{A} / E_{0}} \propto A,
$$

for auroral absorption $A$ from the derivation of (5). Defining the energy indicator from (8) gives

$$
\frac{A}{\sqrt{I}}=\frac{F(E)_{A}}{F(E)_{I}} .
$$

Substituting (10) and (11) into (12) and rearranging gives

$\ln \left(\frac{A}{\sqrt{I}}\right)=\ln \left(\frac{k_{A}}{k_{I}}\right)+\ln \left(\frac{E_{A}}{E_{I}}\right)+\left(E_{I}-E_{A}\right) \frac{1}{E_{0}}$,

which is equivalent to the straight line equation

$$
Y=C+M X,
$$

where the offset $C$ is the two natural logarithm terms put together and the slope $M=E_{I}-E_{A}$. Importantly, $A, \sqrt{I}$, and $E_{0}$ can be measured by a riometer, an optical imager, and incoherent scatter radar, respectively, which allows the unknown terms $C$ and $M$ to be determined empirically. Once these are known for any one point in space, (14) can be applied to the entire sky, thereby generating a map of $E_{0}$ from wide field-of-view measurements of $A$ and $\sqrt{I}$. For the Maxwellian distribution the average energy $\bar{E}$ is given by

$$
\bar{E}=2 E_{0} \text {. }
$$

The entire derivation can easily be repeated for an assumed exponential energy spectral function $(\gamma=0$ in equation (9)), resulting in

$$
\ln \left(\frac{A}{\sqrt{I}}\right)=\ln \left(\frac{k_{A}}{k_{I}}\right)+\left(E_{I}-E_{A}\right) \frac{1}{E_{0}},
$$

with

$$
\bar{E}=E_{0} \text {. }
$$

\section{Instrumentation}

Three instruments with overlapping fields of view are essential to producing calibrated energy maps. The Imaging Riometer for Ionospheric Studies (IRIS) is located at Kilpisjärvi, Finland $\left(69.05^{\circ} \mathrm{N}, 20.79^{\circ} \mathrm{E}\right)$. This imaging riometer [Browne et al., 1995] has 49 beams, operates continuously at $38.2 \mathrm{MHz}$, and samples all beams once per second. The raw beam data are interpolated into a geographic projection for $90 \mathrm{~km}$ altitude at a spatial resolution of $10 \times 10 \mathrm{~km}$, corresponding to $0.1^{\circ}$ latitude and $0.25^{\circ}$ longitude, for an area of $67.8^{\circ}-70.2^{\circ} \mathrm{N}$ and $17.75^{\circ}-23.75^{\circ} \mathrm{E}$, which covers $240 \times 240 \mathrm{~km}$. The techniques and uses of imaging riometers have been summarized by Stauning [1996b].

The Digital All-Sky Imager (DASI) is located at Skibotn, Norway $\left(69.35^{\circ} \mathrm{N}, 20.36^{\circ} \mathrm{E}\right)$. This auroral imager [Kosch et al., 1998] operates with an interference filter which only passes the $\mathrm{O}^{1} \mathrm{~S}$ emission at $557.7 \mathrm{~nm}$ and has been calibrated into units of absolute rayleighs [Baker, 1974]. This feature is crucial to the successful calibration of the characteristic energy outlined earlier. The $\mathrm{O}^{1} \mathrm{~S}$ auroral emission is generally the brightest of the auroral emissions [Vallance Jones, 1991] with a maximum intensity around $100 \mathrm{~km}$ altitude [Störmer, 1955; Currie, 1955]. DASI operates only during the winter for all dark and moonfree periods, amounting to $\sim 1500$ recording hours per year. The raw image data are integrated for $10 \mathrm{~s}$ and then projected onto a geographic grid at $100 \mathrm{~km}$ altitude. A spatial resolution of $10 \times 10 \mathrm{~km}$ is used for an area of $67.6^{\circ}-72.6^{\circ} \mathrm{N}$ and $13.5^{\circ}-$ $26.0^{\circ} \mathrm{E}$, which covers $520 \times 520 \mathrm{~km}$.

The European Incoherent Scatter (EISCAT) facility is located at Ramfjordmoen, Norway $\left(69.59^{\circ} \mathrm{N}, 19.23^{\circ} \mathrm{E}\right)$. The part of the facility used in this study is a tristatic UHF radar operating at $933 \mathrm{MHz}$ [Rishbeth and van Eyken, 1993] with a beam aperture of $\sim 0.6^{\circ}$. The radar can directly measure ion and electron temperature, ion velocity, and electron density. In this study, only the electron density altitude profiles are used. EISCAT is operated for $\sim 2500$ hours per year, and electron density is typically measured in the height range $\sim 60-587 \mathrm{~km}$. Common Program 1 (CP1) measures parallel to the magnetic field line (zenith angle $\sim 13^{\circ} \mathrm{S}$ ) with a time resolution of $5 \mathrm{~s}$; however, the data are usually postintegrated to $60 \mathrm{~s}$ in order to improve the signal to noise ratio.

Figure 1 shows the geographic arrangement of IRIS, DASI, and EISCAT overlaid on a map of northern Scandinavia. The large and small trapezia are the processed fields of view of DASI and IRIS, respectively. The 49 ellipses are the IRIS beams projected to $90 \mathrm{~km}$ altitude. The dot is EISCAT's position mapped up the magnetic field line to $100 \mathrm{~km}$ altitude.

\section{Results and Discussion}

The data presented here come from two EISCAT CP1 runs on February 13, 1996, and November 9, 1998. Any clouds present in the sky have been identified since they ruin DASI's absolute optical intensity measurement. Ionospheric scintillations observed by IRIS as a result of a strong radio source (e.g., 


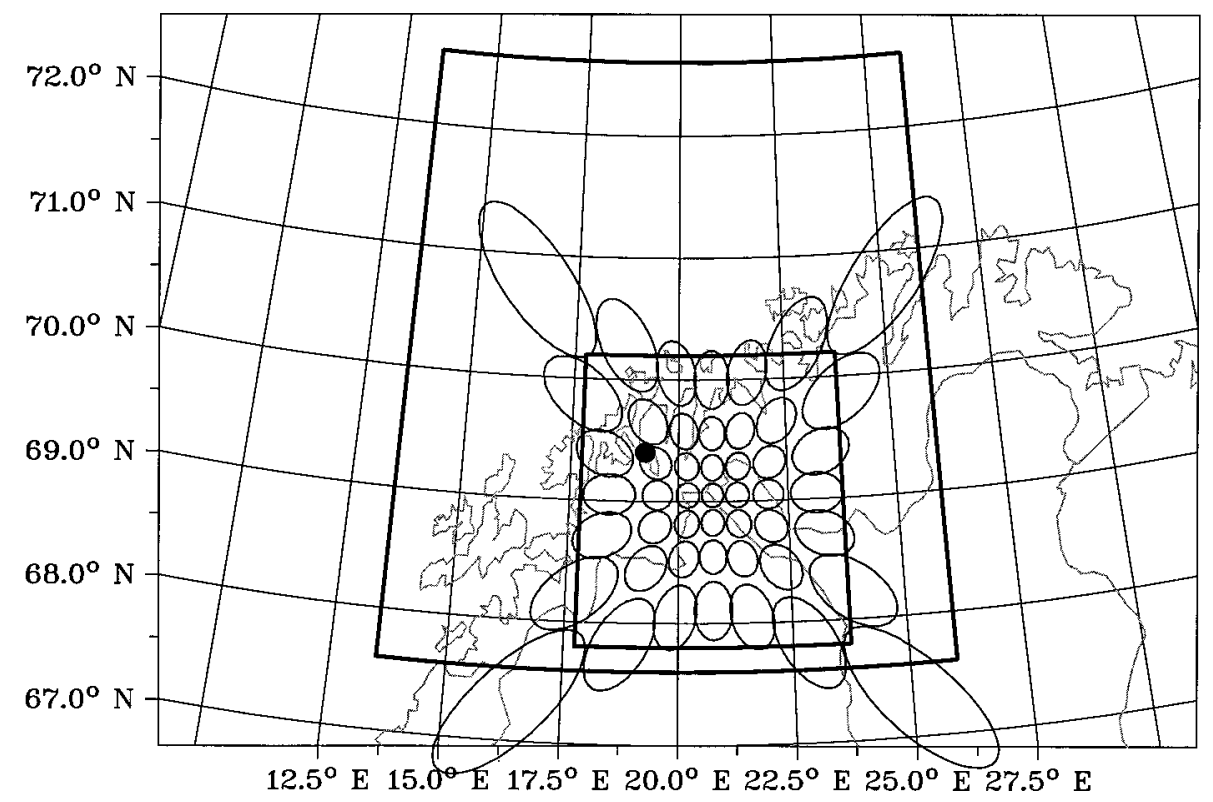

Figure 1. A geographic map of northern Scandinavia showing the field of view of the Digital All-Sky Imager (DASI) processed data (large trapezium), the field of view of the Imaging Riometer for Ionospheric Studies (IRIS) processed data (small trapezium), the IRIS beam pattern projected up to $90 \mathrm{~km}$ altitude (ellipses), and the European Incoherent Scatter (EISCAT) radar's position projected up the magnetic field line to $100 \mathrm{~km}$ altitude.

Cassiopeia) in one of the beams increase the error in the absorption measurement. Excluding periods of cloud from DASI and removing beams with scintillations from the IRIS data, all three experiments had good data simultaneously for 2006-0020 and 1742-2200 UT on the nights of February 13, 1996, and November 9, 1998, respectively. In the periods investigated, $K p$ was in the range $2^{+}-4^{-}$and $4^{+}-6^{+}$for February 13, 1996, and November 9, 1998, respectively, providing a good spread in geomagnetic activity. It is important that two independent data sets are combined to ensure that any empirical relationship between the characteristic energy of the chosen distribution function and the energy indicator is not a special case.

Plates 1 and 2 present the raw and processed data for the February 13, 1996, and November 9, 1998, data sets, respectively. Plates 1a and 2a show the electron density altitude profile measured by EISCAT in the altitude range $60-340 \mathrm{~km}$ with a $60 \mathrm{~s}$ temporal resolution. Uncolored entries indicate no data. Electron densities are extracted from the radar backscattered power profile, which is primarily a function of electron density, with a spatial resolution of $3 \mathrm{~km}$. In the $F$ and $E$ regions down to $87 \mathrm{~km}$ the electron density is compensated for the ratio of electron to ion temperatures. In the $D$ region between 87 and $60 \mathrm{~km}$ it is assumed that the ion and electron temperatures are equal. This is a good assumption in the $D$ region because of the higher collision frequencies. The effects of the electron to ion temperature ratio, Debye length, and negative ions on the measured electron density are given by $\mathrm{del}$ Pozo et al. [1999]. From Plates 1a and 2a it is clear that there is significant ionization from particle precipitation down to 100 $\mathrm{km}$ altitude and lower, indicating the presence of aurora and absorption.

Plates $1 b$ and $2 b$ show the equivalent energy spectra of the precipitating electrons and are obtained by inverting the data of Plates 1a and 2a [del Pozo et al., 1997]. The inversion has been done for energies in the range $0.8-380.5 \mathrm{keV}$ with 29 steps. Above $160 \mathrm{keV}$ the energy fluxes are essentially in the noise and are not shown. From (6), 0.8-160 keV corresponds to an altitude range of $129.9-77.5 \mathrm{~km}$, which covers most of the $557.7 \mathrm{~nm}$ auroral emission and absorption altitudes. Uncolored entries correspond to no fit. Conceptually, the inversion is done by adjusting the flux of each one of the 29 monoenergetic beams which have been defined until the integral of all 29 ionization profiles, one for each energy, is equal to the electron density profile measured by EISCAT. Theoretical ionization profiles for mono-energetic beams of electrons have been computed [e.g., Rees, 1963], but these depend on the model atmosphere assumed. For the inversion the Sodankylä ion chemistry model [Turunen et al., 1992] is used which describes the chemical composition of the $D$ and $E$ regions. This atmospheric model includes 24 and 11 positive and negative ions, respectively, and takes into account over 175 chemical reactions. We believe it is the most complete representation of the lower ionosphere currently available.

Plates $1 \mathrm{c}$ and $2 \mathrm{c}$ show the Maxwellian characteristic energy $E_{0}$. This curve is obtained by least squares fitting the Maxwellian distribution function (see equation (9) for $\gamma=1$ ) to the data shown in Plates $1 \mathrm{~b}$ and $2 \mathrm{~b}$. This is done independently for each time increment. A flux threshold of $10^{2}\left(\mathrm{keV} . \mathrm{cm}^{2} . \mathrm{sr} . \mathrm{s}\right)^{-1}$ has been imposed on the fitting algorithm to eliminate those energies which introduce much noise. This effectively corresponds to the detection limit of EISCAT. Plates $1 \mathrm{~b}$ and $2 \mathrm{~b}$ show that most of the significant flux occurs at energies less than $80 \mathrm{keV}$. At higher energies the flux is mostly many orders of magnitude lower. It is possible to fit a Maxwellian function with high confidence in virtually all instances. A three-point running median filter has been applied to the data in Plates 1c and $2 \mathrm{c}$ in order to remove the few obviously poor fits. Comparing Plates $1 b$ and $2 b$ with Plates $1 \mathrm{c}$ and $2 \mathrm{c}$, it is obvious that the fluctuations in characteristic energy are correct. The com- 
parison is most clear for fluxes in the energy band 3.5-40 keV. Greater fluxes at higher energies, or conversely lower fluxes at smaller energies, result in a larger characteristic energy, and vice versa.

Plates 1d and 2d show the absorption over EISCAT from IRIS. Since there is no single narrow beam riometer beam available over EISCAT (see Figure 1), the absorption value is determined by interpolation and suitable weighting of the surrounding IRIS beams. The data have been subjected to a running three-point median filter to remove noise. Comparing Plates $1 \mathrm{~b}$ and $2 \mathrm{~b}$ with Plates $1 \mathrm{~d}$ and $2 \mathrm{~d}$, variations in absorption relate well to the flux of electrons in the energy band 25-80 $\mathrm{keV}$. This is consistent with previous assumptions and observations discussed earlier. The zenith angle from IRIS to $90 \mathrm{~km}$ altitude above EISCAT is $40^{\circ}$. Rocket measurements through the absorption region indicate that the layer is $\sim 20 \mathrm{~km}$ thick [Friedrich and Torkar, 1983]. For a uniform layer of finite thickness the riometer reading would be $30 \%$ too large compared to the vertical. This obliquity factor has been compensated for in the data processing.

Plates 1e and 2e show the square root of optical intensity at $557.7 \mathrm{~nm}$ over EISCAT from DASI. The imager has sufficient resolution to measure the auroral optical intensity over EISCAT directly. The data have been subjected to a running three-point median filter to remove noise. One of the problems with ground-based auroral imaging from one site only is that the vertical extent of auroral forms can be large (up to $100 \mathrm{~km}$ or more). Since DASI is not colocated with EISCAT, any vertical extent will appear in effectively the wrong horizontal position for an assumed auroral altitude of $100 \mathrm{~km}$. The problem is limited because auroral forms tend to be east-west aligned, and DASI is mostly eastward of EISCAT. However, the imager will integrate all optical emissions along the line of sight. The zenith angle from DASI to $100 \mathrm{~km}$ altitude above EISCAT is $25^{\circ}$, introducing an error of $10 \%$ compared to the vertical. Since we use the square root of optical intensity (see equation (8)), the systematic error reduces to $5 \%$, which is small compared to the problem of variable emission height and vertical extent of the aurora (discussed below) and is ignored. For the data sets used in this study a three-dimensional (3-D) tomographic reconstruction of the aurora is not possible due to the lack of additional suitably located imagers.

Plates $1 \mathrm{f}$ and $2 \mathrm{f}$ show the ratio of absorption to square root of optical intensity. The energy indicator (see equation (8)) is generated from the curves shown in Plates $1 \mathrm{~d}$ and $2 \mathrm{~d}$ as well as Plates 1e and 2e. Equation (13) predicts a logarithmic relationship between the energy indicator in Plates $1 \mathrm{f}$ and $2 \mathrm{f}$ and the Maxwellian characteristic energy in Plates 1c and 2c. Comparing Plates $1 \mathrm{c}$ and $2 \mathrm{c}$ and Plates $1 \mathrm{f}$ and $2 \mathrm{f}$, the curves have a remarkably similar shape, and the fluctuations with time correlate rather well although not all details are identical. For example, at 2100 UT on February 13, 1996 (Plate 1), the peak in energy indicator (Plate 1f) is much narrower than that in characteristic energy (Plate 1c). Also, the steady rise in characteristic energy between 2130 and 2300 UT is not well reproduced by the energy indicator. On November 9, 1998 (Plate 2), the peaks in characteristic energy (Plate $2 \mathrm{c}$ ) centered around 1830 and 2030 UT exist in the energy indicator plot (Plate 2f) but are not well reproduced in relative magnitudes.

Comparing the characteristic energy energies extracted from EISCAT data with past experiments involving riometers or optical imagers is difficult due to substantial differences in the experiments. In the past mostly wide beam riometers were used, no studies of the absolute $557.7 \mathrm{~nm}$ emission intensity versus energy seem to be available, and certainly no quantitative experiments were performed which combined riometer, optical imager, and incoherent scatter radar data. Coordinated studies between IRIS and EISCAT have been performed, where EISCAT electron density data have been inverted into flux spectra [e.g., Collis et al., 1996; Collis and Hargreaves, 1997]. However, these studies did not attempt to find any empirical relationship between the observables of EISCAT, DASI, and IRIS. For comparison purposes we limit ourselves to a few previous EISCAT riometer observations, which have similar Kp values to February 13, 1996, and November 9, 1998. Burns et al. [1990] used EISCAT and wide-beam riometers to study substorm onset. Several riometers were located in northern Scandinavia, but none was colocated with EISCAT. Exponential functions were fitted to the energy spectra inferred from EISCAT data although sometimes the data clearly had different spectral shapes. For one substorm $\left(K p=4^{+}\right)$, absorption varied in the range $1-2 \mathrm{~dB}$, depending on the riometer used, with the exponential characteristic energy $\left(E_{0}\right)$ in the range $2-6 \mathrm{keV}$. For another substorm $\left(K p=3^{+}\right)$the values are in the ranges $0-2 \mathrm{~dB}$ and $5-12 \mathrm{keV}$. We convert between exponential and Maxwellian characteristic energies using (15) and (17). For the substorm onset at $\sim 2105$ UT on February 13, 1996 (see Plate 1), the absorption over EISCAT varied in the range $0.2-0.9 \mathrm{~dB}$ with the Maxwellian $E_{0}$ in the range 2.3-6.5 $\mathrm{keV}$, corresponding to an exponential $E_{0}$ of $4.6-13 \mathrm{keV}$. For the substorm onset $\sim 2030$ UT on November 9, 1998 (see Plate 2 ), the absorption was $0.1-1 \mathrm{~dB}$ with the Maxwellian $E_{0}=$ 2.5-6.5 keV, corresponding to an exponential $E_{0}=5-13$ $\mathrm{keV}$. Despite significant differences in the experiments, our results compare favorably with Burns et al. [1990]. Hargreaves and Devlin [1990] have studied morning sector electron precipitation using EISCAT and a colocated wide-beam riometer. Exponential functions were also fitted to the energy spectra inferred from EISCAT data. During a nonsubstorm period they recorded absorption at $<0.8 \mathrm{~dB}$ and found the exponential $E_{0}=4-14 \mathrm{keV}$, corresponding to a Maxwellian $E_{0}=2-7$ $\mathrm{keV}$. For similar nonsubstorm periods, with absorption $<0.8$ $\mathrm{dB}$, we have a Maxwellian $E_{0}=2.5-7 \mathrm{keV}$ on February 13, 1996 (see Plate 1) and $E_{0}=2-4 \mathrm{keV}$ on November 9, 1998 (see Plate 2). Despite the different riometer types and time sectors, our results compare favorably with Hargreaves and Devlin [1990]. We conclude that our data analysis is consistent with previous results.

Plate 3 shows comparisons of IRIS absorption and DASI optical intensity with EISCAT derived incident fluxes of electrons in two energy bands. Plates $3 \mathrm{a}$ and $3 \mathrm{~b}$ refer to February 13, 1996, whereas Plates 3c and 3d are for November 9, 1998. Plates $3 \mathrm{a}$ and $3 \mathrm{c}$ show the square (see equation (7)) of absorption amplitude (red curve) and the flux of precipitating particles integrated over the energy range 28.3-80 keV (blue curve). From (6) the selected energy range corresponds to an altitude range of $94.6-84.3 \mathrm{~km}$, which encompasses the expected height range for absorption. For both data sets the pairs of curves have a very similar time variation throughout, indicating that the selected energy (alternatively altitude) range is correct. Including energies greater than $80 \mathrm{keV}$ makes virtually no difference as the fluxes are generally very small here (see Plates 1 and 2). Including energies lower than $28.3 \mathrm{keV}$ makes the comparison worse. For both data sets there is an increase in the offset between the pairs of curves after a sudden spike in absorption at $\sim 2105$ and $\sim 2030$ UT on February 13, 1996 
(Plate 3a), and November 9, 1998 (Plate 3c), respectively, indicating a hardening of the energy of the precipitating electrons. Both these times correspond to substorm onset according to the magnetometer records. This can be seen in Plates $1 \mathrm{~b}$ and $2 \mathrm{~b}$ as an increased flux at energies greater than $\sim 30$ and 20 keV on February 13, 1996, and November 9, 1998, respectively.

Plates $3 \mathrm{~b}$ and $3 \mathrm{~d}$ show the optical intensity at $557.7 \mathrm{~nm}$ (green curve) and the flux of precipitating particles integrated over the range $8.4-14.1 \mathrm{keV}$ (blue curve). From (6) the selected energy range corresponds to an altitude range of 106.6$101.5 \mathrm{~km}$, which is the expected altitude range for the lower border of auroral forms where the optical intensity generally maximizes [Currie, 1955; Störmer, 1955]. The pairs of curves do not have a very convincing similarity. Adjusting the energy range integrated over does not bring any improvement. On close inspection, it is realized that significant up and down swings in the flux curves (blue) are also accompanied by similar movements in the optical intensity (green). However, there is no simple clear relationship between the magnitude of the flux fluctuations and optical variations. It is as if the "AC" component is the same but the "DC" component is not. This implies that the offset between pairs of curves is not constant for long periods of time as was the case for absorption (see Plates $3 \mathrm{a}$ and $3 \mathrm{c}$ ). One possible cause is that the effective altitude and height extent of the aurora at $557.7 \mathrm{~nm}$ are much more variable than that for absorption. This is easily confirmed by inspecting (6). At the lower energies typical for aurora, a step change in energy produces a much greater height variation than would be the case for the same change at higher energies typical for absorption. For example, in the case of aurora, changing the energy by $3 \mathrm{keV}$ from 9 to $12 \mathrm{keV}$ will produce a height change of $2.9 \mathrm{~km}$. The same change of energy for absorption from 40 to $43 \mathrm{keV}$ produces an altitude change of only $0.7 \mathrm{~km}$. The comparison gets exponentially worse for lower energies (or greater altitudes). This means that the total path length over which the line-of-sight optical data are integrated by DASI will vary according to changes in the precipitating particle energy spectrum. This will also give rise to changes in the apparent intensity of the optical emission, which do not relate purely to changes in the particle flux. The point illustrates one of the problems of using the optical aurora. Unfortunately, no other suitable wavelength is necessarily more stable in altitude. In principle, the problem could be solved by using multiple imagers for tomography; however, this is generally impractical.

Measurements of the auroral excitation efficiency at 557.7 $\mathrm{nm}$ [Steele and McEwen, 1990] reveal variations between 0.67 and $1.7 \mathrm{kR} \mathrm{erg}^{-1} \mathrm{~cm}^{-2} \mathrm{~s}^{-1}$. Hence, even for a fixed precipitating energy flux, a significant uncertainty (up to a factor of 2.5 ) in optical emission intensity exists, which is due to small changes in the precipitating electron energy spectrum and atmospheric composition. Another potential source of error is the breakdown of the steady state assumption for (2). Clearly, $d N_{e} / d t=0$ is not always strictly true and may account for the changes in offset between the two curves in Plates $3 b$ and $3 d$, especially during substorms. Likewise, neglecting the transport term $\operatorname{div}\left(N_{e} \cdot \bar{\nu}\right)$ in (2) may introduce errors, especially during geomagnetically active periods. In addition, the flux of highenergy particles, which generate the absorption layer, will also contribute to the optical aurora as they have to pass through the $E$ region to reach the $D$ layer. Although the ionization curves of Rees [1963] indicate that most of the energy for hard particles will be deposited in the $D$ region, up to $25 \%$ will be lost above $100 \mathrm{~km}$. However, the flux in the energy range
8.4-14.1 keV is about an order of magnitude greater than that in the range $28.3-80 \mathrm{keV}$. Hence the particles responsible for producing absorption will contribute only a few percent $(25 \%$ of $10 \%=2.5 \%$ ) to the optical emission. Attempts to subtract the higher-energy flux from the lower-energy flux in order to improve the comparison of optical intensity with incident electron flux (Plates 3b and 3d) have not been helpful. Given that variations in the altitude and vertical extent of the aurora present a potentially much more serious problem, this effect has been ignored. The $557.7 \mathrm{~nm}$ oxygen emission $\left(\mathrm{O}^{1} \mathrm{~S}\right)$ is the brightest and most prevalent of all the auroral emissions [ $\mathrm{Val}$ lance Jones, 1991]. Given the lack of any other more suitable optical emission in the $E$ layer, $\mathrm{O}^{1} \mathrm{~S}$ is used in this work despite the problems noted above.

Additional sources of uncertainty include the absolute calibration of DASI [Kosch et al., 1998], receiver stability for IRIS [Browne et al., 1995], and errors in the EISCAT data inversion [del Pozo et al., 1997]. For IRIS, DASI, and EISCAT these uncertainties are $0.04 \mathrm{~dB},<20 \%$, and $<10 \%$, respectively. Errors in determining the IRIS quiet day curve by computer algorithm are estimated to be $<0.07 \mathrm{~dB}$, although manual adjustment can achieve $0.01 \mathrm{~dB}$ [Browne et al., 1995]. The data presented in Plates $1 \mathrm{c}$ and $2 \mathrm{c}$ and Plates $1 \mathrm{f}$ and $2 \mathrm{f}$ have been combined into a scatterplot, which is shown in Figure 2. A total of 436 points from both data sets are included. Absorption and optical data with an absolute value less than $0.07 \mathrm{~dB}$ and $100 \mathrm{R}$, respectively, have been rejected since these data are below the effective detection threshold of the instruments. The removal of these data is important since very low optical intensities will make the energy indicator $A / \sqrt{I}$ go to infinity (see equation (8)) whereas very low absorption values will make $\ln (A / \sqrt{I})$ go to negative infinity (see equation (13)). Only riometer data from November 9, 1998, are affected with a total of 51 data points being rejected. The axes of Figure 2 are chosen such that fitting (13) will produce a straight line in the scatterplot. The least squares fit of (13) is shown as the solid line with the dashed and dotted lines representing one and two standard deviations, respectively. The equation of the fit is

$$
Y=-8.8 X+1.0 \text {, }
$$

where $Y=\ln (A / \sqrt{I})$ and $X=1 / E_{0}$ with $E_{0}$ as the Maxwellian characteristic energy.

A useful cross-check is to inspect the slope of (13), i.e., $E_{A}-$ $E_{I}=8.8$, which represents the difference in Maxwellian characteristic energy between the absorption and optical emission. Bearing in mind that the average energy is twice the Maxwellian characteristic energy (see equation (15)), the average energy difference between the incident particles producing absorption $\left(\bar{E}_{A}\right)$ and the optical aurora $\left(\bar{E}_{I}\right)$ is $\bar{E}_{A}-\bar{E}_{I}=$ $17.6 \mathrm{keV}$. This is consistent: For typical optical energies of $<15 \mathrm{keV}$, the absorption energies would be $<32.6 \mathrm{keV}$ on average. This corresponds well with the curves shown in Plate 3 , bearing in mind that the average is biased to lower energies because of the very much lower particle flux at higher energies. It seems obvious that the problems of the variable altitude and height extent of the optical aurora and nonconstant photon production efficiency, discussed earlier, will contribute to the spread in the distribution of Figure 2. In addition, for active periods the assumptions used in going from (1) to the simplification of (2) may temporarily break down. This is likely during substorm onsets, which occurred in both data sets. It is also clear that the curve fit would benefit from more data, especially for greater $1 / E_{0}$. 


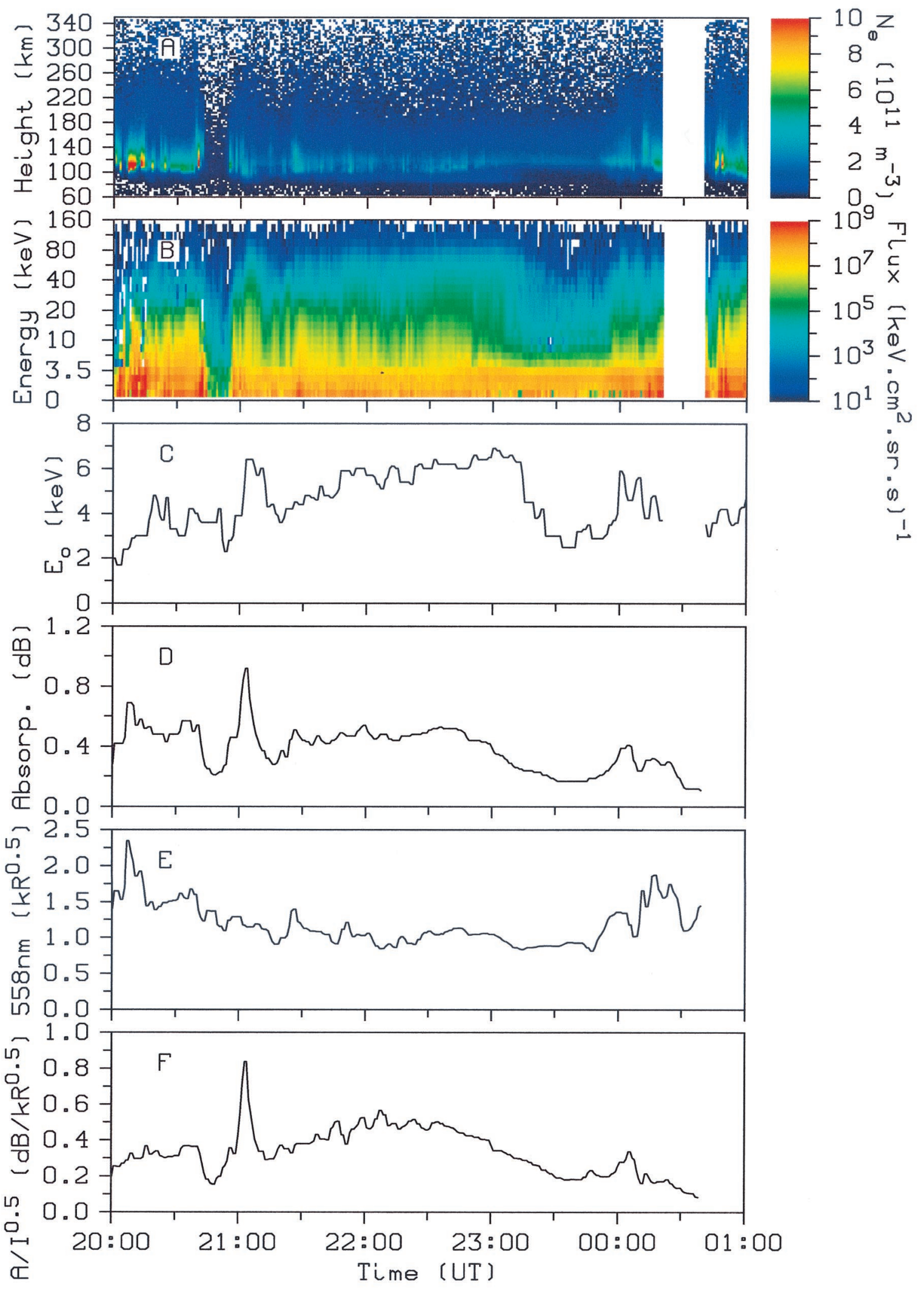

Plate 1. (a) The EISCAT electron density profile between 60 and $340 \mathrm{~km}$, (b) the equivalent energy spectra of precipitating electrons in the energy range $0.8-160 \mathrm{keV},(\mathrm{c})$ characteristic energies from fitting the Maxwellian distribution function to the flux spectra, (d) riometer absorption over EISCAT measured by IRIS, (e) the square root of optical emission intensity for $557.7 \mathrm{~nm}$ over EISCAT measured by DASI, and (f) the ratio of absorption to square of optical intensity shown for February 13, 1996. 


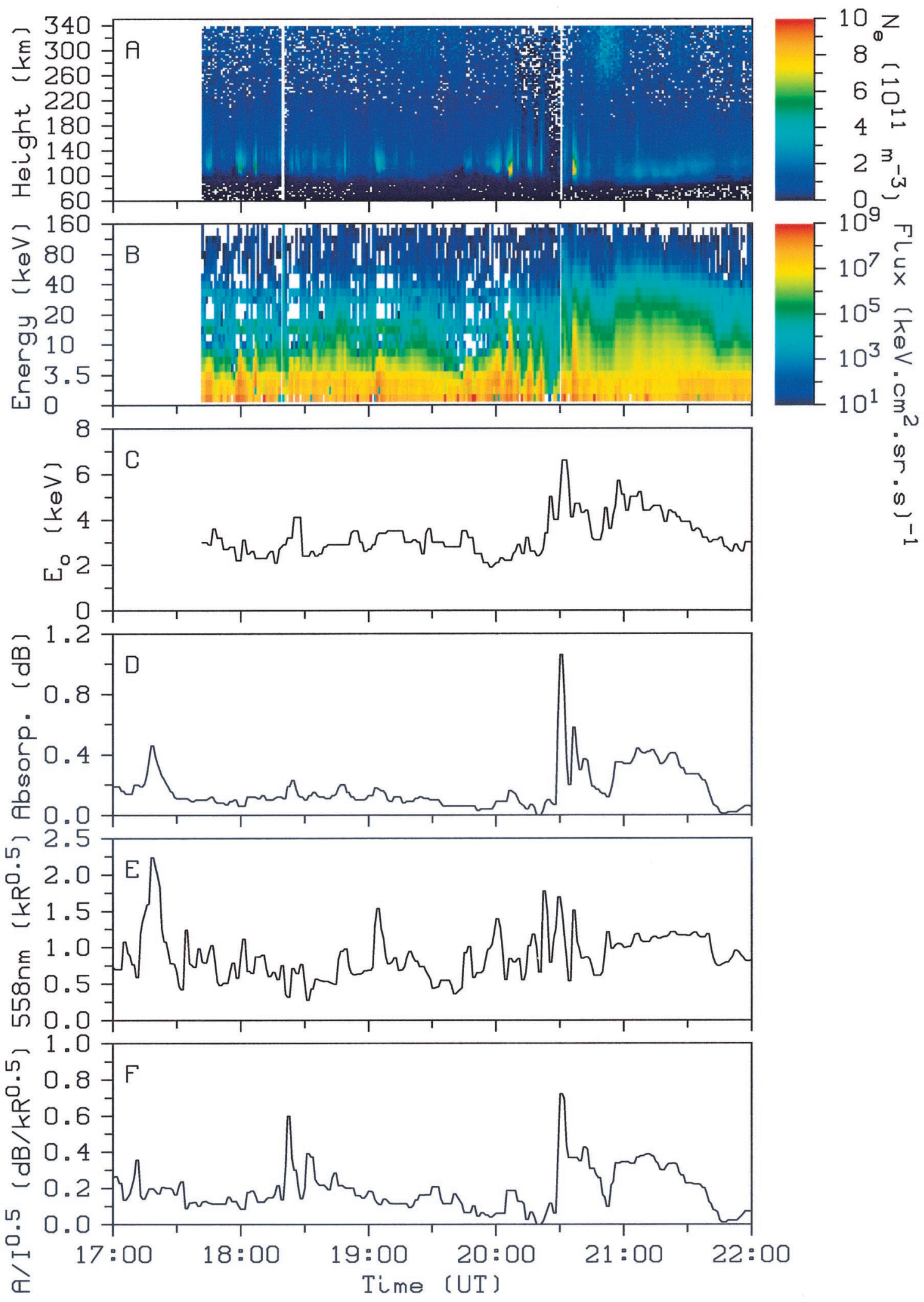

Plate 2. (a-f) Identical to Plate 1 except for November 9, 1998. 

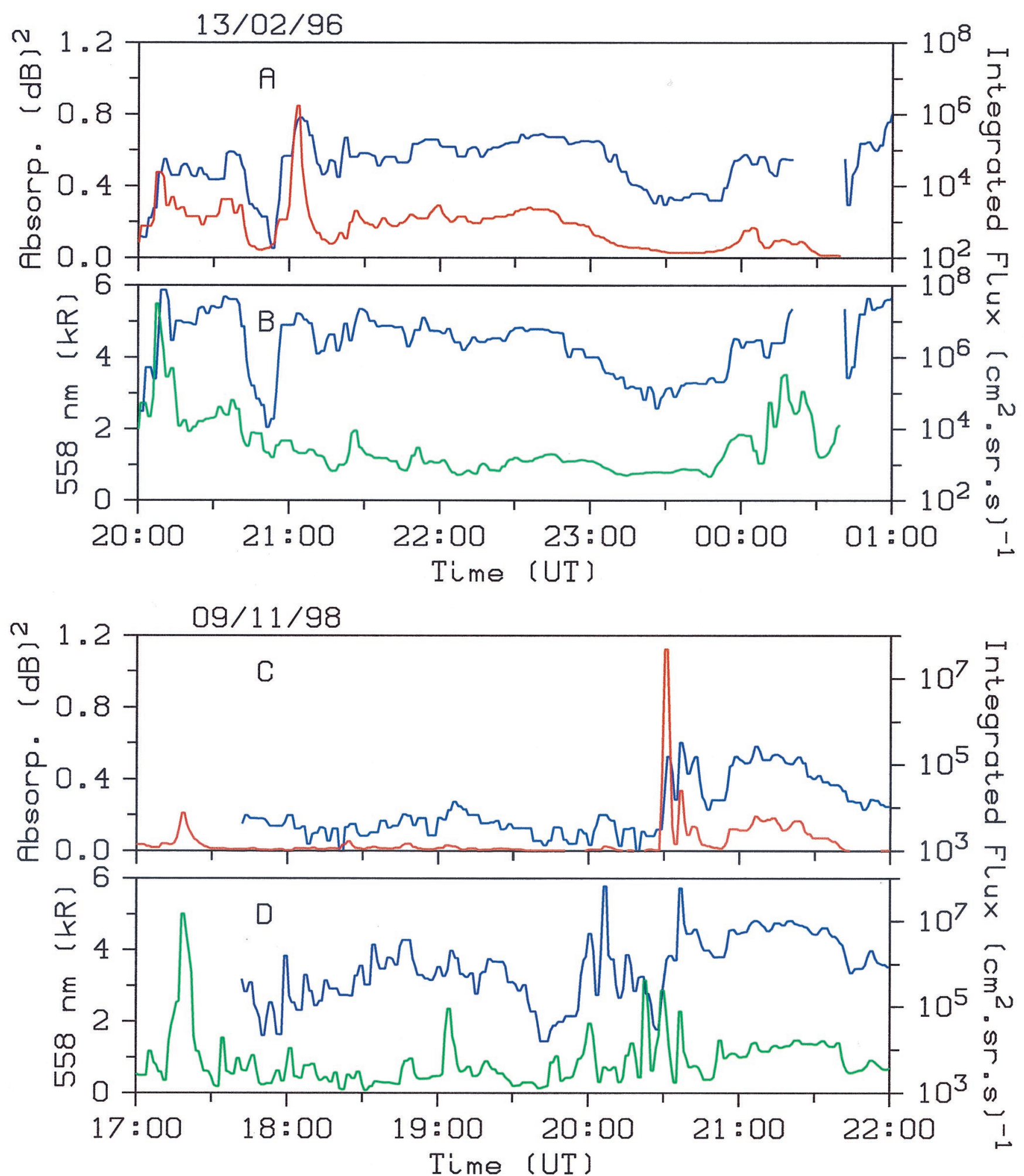

Plate 3. (a) The integrated flux of precipitating particles in the energy range $28.3-80 \mathrm{keV}$ (blue curve) and IRIS riometer absorption over EISCAT (red curve) for February 13, 1996. (b) The integrated flux of precipitating particles in the energy range $8.4-14.1 \mathrm{keV}$ (blue curve) and DASI optical intensity for $557.7 \mathrm{~nm}$ over EISCAT (green curve) for February 13, 1996. (c, d) The same as Plates 3a and 3b, respectively, except for November 9, 1998. 


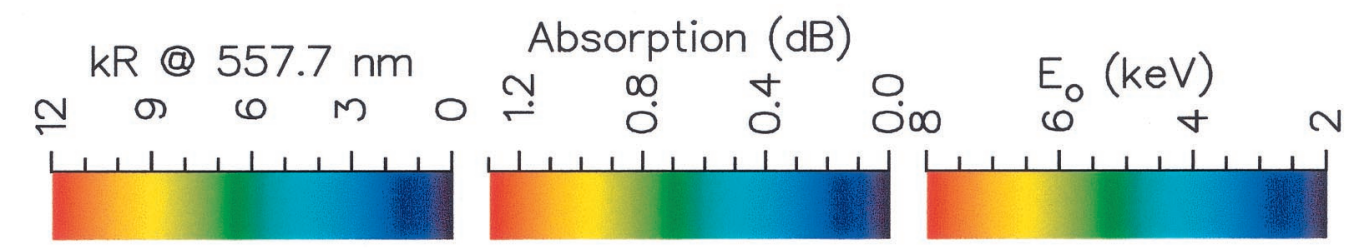

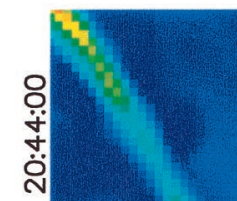
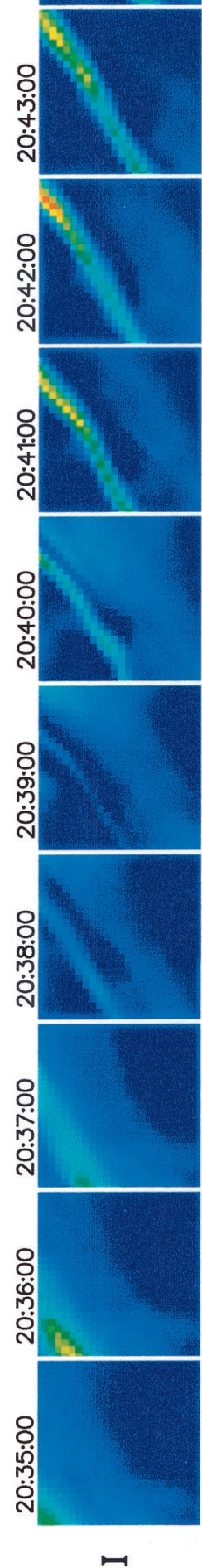
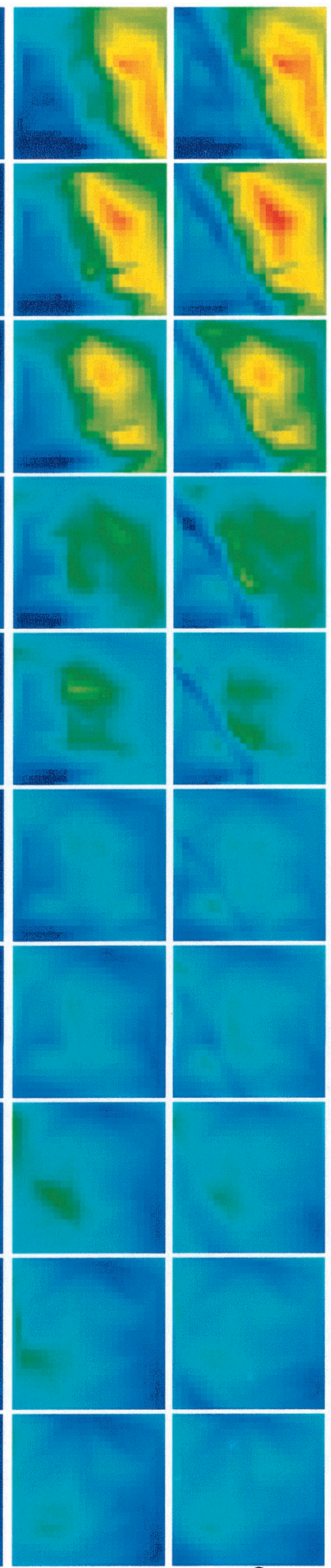

$\varangle$
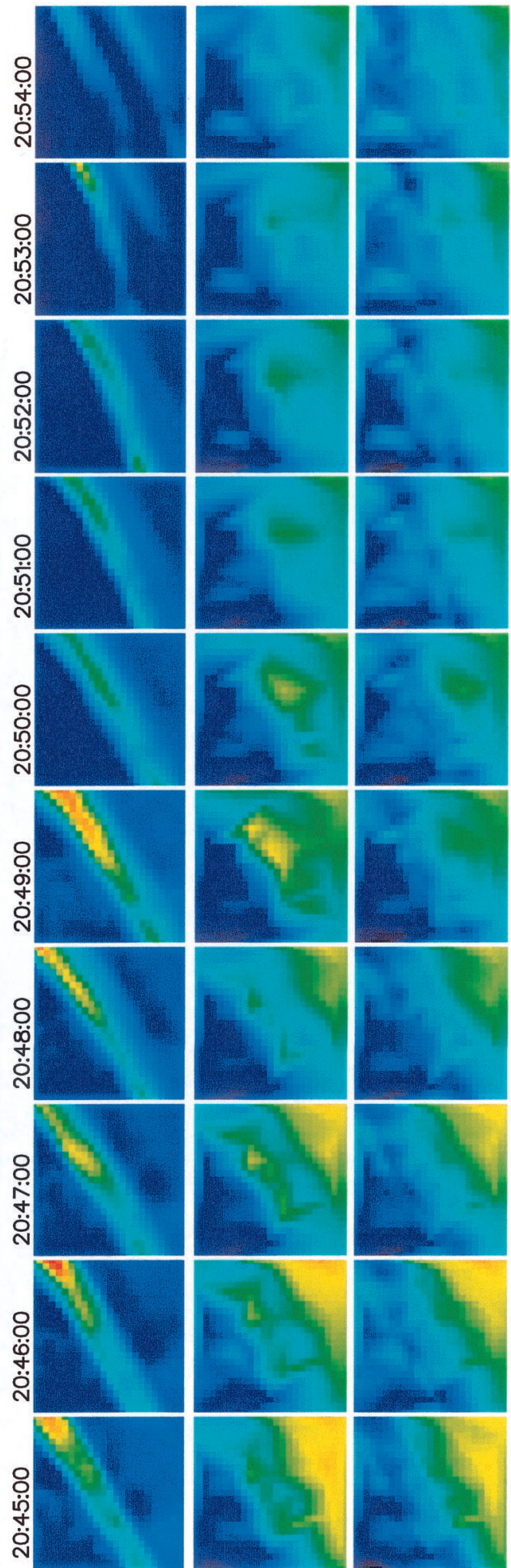

흘

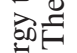

过

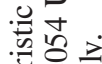

웡

क

㐘.

एक

矛守

즘

思

$\sum_{0}$.

ज्ञ त्

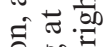

.

당하

品

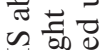

告

으음

国

$ㄱ$.

合宫

구의

元

党要

总寻青

政

음디

o의른

जद

证

范

늘

즐

느

국

जi?

象

उ

$+0$

를

은 


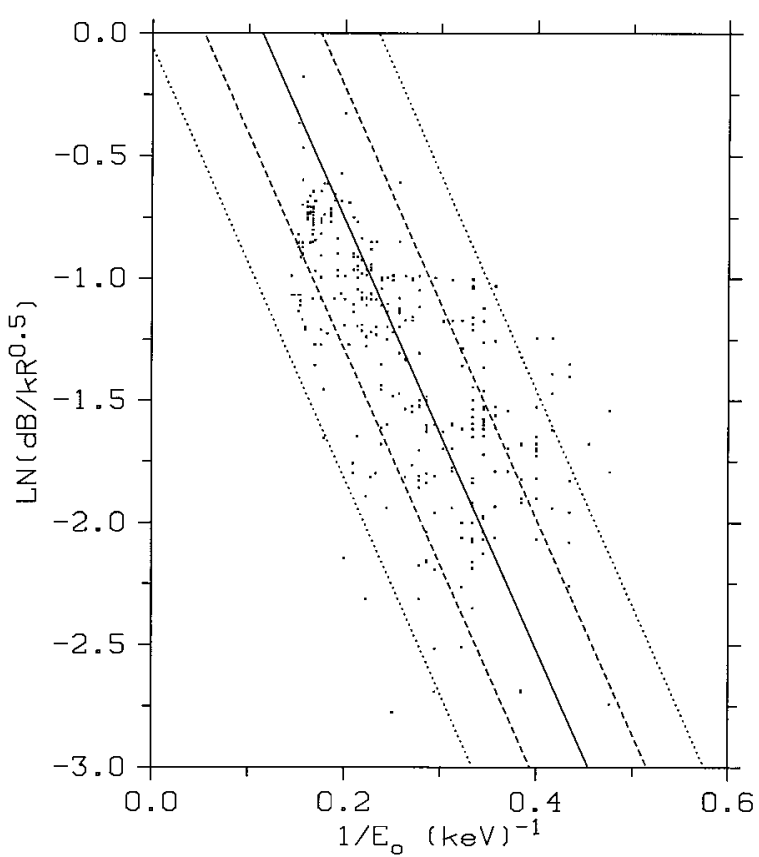

Figure 2. Scatterplot of the natural logarithm of the ratio of absorption to the square root of optical intensity versus the inverse of Maxwellian characteristic energy of the precipitating particles for the combined data sets of February 13, 1996, and November 9, 1998. The solid line shows the best fit of equation (13). The dashed and dotted lines show 1 and 2 standard deviations, respectively, from the best fit.

We have found the distribution in the scatterplot of Figure 2 to be very sensitive to cloud. This is not surprising as photometrically clear viewing is required in order to measure the optical intensity correctly without any scattering or absorbing effects. Cloud results in the affected data points being placed erroneously higher up the $Y$ axis (toward less negative values), which causes the fit of (13) to have a much too small slope. Cloud will limit the periods of possible energy map production. If the entire fitting procedure described above is repeated for an assumed exponential energy spectral function (see equation (9) for $\gamma=0$ ), then fitting (16) to the scatterplot (not shown) gives

$$
Y=-11.0 X+0.9 \text {. }
$$

For the exponential distribution the characteristic energy is equal to the average energy (see equation (17)). Hence the slope of (19) gives $\bar{E}_{A}-\bar{E}_{I}=11.0 \mathrm{keV}$. The average energy difference between the incident particles producing absorption and the optical aurora is $11.0 \mathrm{keV}$, which is less than that for the Maxwellian distribution. The smaller difference is less realistic and probably stems from the less realistic representation of an exponential function, especially at low energies. We conclude that the Maxwellian distribution is the better choice.

Finally, we show an example of applying (18) to image format data, which is the ultimate goal of the work presented here. Plate 4 shows DASI, IRIS, and Maxwellian characteristic energy maps for the geographic area of $67.8^{\circ}-70.2^{\circ} \mathrm{N}$ and $17.75^{\circ}-23.75^{\circ} \mathrm{E}$. The images are in plan view with north and east being up and right, respectively. The data comes from February 13, 1996, in the interval 2035-2054 UT with 1 min time increments and $10 \times 10 \mathrm{~km}$ spatial resolution. Magne- tometer data indicate that a substorm onset occurred at 2035 UT. Although it is beyond the scope of this paper to perform a full detailed analysis of this event, some interesting points are noted. In this example the auroral arc is latitudinally thin compared to the more diffuse absorption region, and the optical emission occurs poleward of the absorption region. In the period 2040-2044 UT there is a very clear reduction in characteristic energy for the optical arc. After 2045 UT the absorption shows an arc-like feature concurrent with the optical arc in addition to a broad diffuse region to the southeast. Correspondingly, the characteristic energy map no longer shows the optical arc to be well defined as a channel of reduced energy. Hardy et al. [1985] and Spiro et al. [1982] have produced global statistical maps of the average energy of precipitating electrons for various $K p$ and $A e$ values, respectively. Although a detailed comparison with Plate 4 is impossible because of the different time and spatial scales as well as the substorm onset, it is worth noting that they predict an average energy of $\sim 3 \mathrm{keV}$, which corresponds rather well with our estimate of $E_{0} \approx 2 \mathrm{keV}$, or equivalently average $\bar{E} \approx 4 \mathrm{keV}$, for the background region furthest away from any significant particle precipitation (see northwest corner of energy plots in Plate 4 after 2045 UT).

The energy maps require the viewer to reinterpret the image information presented. The familiar images of all-sky optical aurora and imaging riometer absorption are flux indicators for different energy ranges. The energy maps presented in Plate 4 do not relate to the absolute flux magnitude of the precipitating particles at all. Very weak and exceptionally strong fluxes can produce identical maps of characteristic energy. It is the relative flux intensity of the hard and soft components of a broad spectrum of incident particles that is highlighted in the energy maps. A good example of this occurs at 2049-2050 UT, where there is a sudden decrease in optical intensity and absorption without any significant change in the morphology of the energy map. It is clear from just the one example shown in Plate 4 that the maps of characteristic energy open up new possibilities for interpreting auroral phenomena.

The $557.7 \mathrm{~nm}$ auroral emission and absorption account for electron energies precipitating into the $E$ and $D$ regions, respectively, corresponding to energies of $>1 \mathrm{keV}$. The existence of the $630 \mathrm{~nm}$ auroral emission, which occurs predominantly in the $F$ region, clearly indicates a significant flux of precipitating particles at energies $<1 \mathrm{keV}$. Plates $1 \mathrm{a}$ and $2 \mathrm{a}$ show that there is a significant electron density in the $F$ layer, which sometimes may even be dominant (e.g., 2050 UT on November 9, 1998). This is confirmed by satellite [e.g., Frank and Ackerson, 1971; Lui et al., 1977] and rocket data [e.g., Ogilvie, 1968; Westerlund, 1969; Arnoldy et al., 1974; Maynard et al., 1977]. Energy spectra of incident electrons can also be deduced from combining ground-based observations of several optical emissions [Robinson and Vondrak, 1994]. In order to improve the calibration of the energy maps, especially at lower energies where Figure 2 has a sparsity of data, it is necessary to image auroral emissions at $630 \mathrm{~nm}$. Such an upgrade is planned for DASI.

\section{Conclusions}

For the first time, ground-based high-resolution maps of the characteristic energy of precipitating auroral electrons have been produced. This has been done by empirically finding the relationship between the energy indicator $A / \sqrt{I}$, where $A$ is absorption and $I$ is the absolute optical intensity at $557.7 \mathrm{~nm}$, and the characteristic energy $E_{0}$ of an assumed Maxwellian 
energy distribution. $E_{0}$ is obtained by fitting the Maxwellian function to the energy spectra of the precipitating electrons, which has been obtained by inverting the electron density altitude profile measured by EISCAT. Once the relationship between $E_{0}$ and $A / \sqrt{I}$ is known, the imaging capabilities of IRIS and DASI are exploited to map $E_{0}$ to the entire common field of view. This has been done for two data sets (February 13, 1996, and November 9, 1998) in order to improve the statistics of the empirical fit as well as to demonstrate that the good fit was not by chance. The energy maps open a new way of studying auroral processes, and we have shown the first substorm studied in terms of the spatial morphology of the energy of the precipitating particles.

Acknowledgments. IRIS is operated by the Dept. of Communications Systems at Lancaster University (UK) and is funded by the Particle Physics and Astronomy Research Council (PPARC) in collaboration with Sodankylä Geophysical Observatory (Finland). DASI is operated by the Max-Planck-Institut für Aeronomie (Germany) in collaboration with the Auroral Observatory at the University of Troms $\varnothing$ (Norway). EISCAT is an international scientific association supported by the research councils of Finland, France, Germany, Japan, Norway, Sweden, and the United Kingdom. M.J.K. gratefully acknowledges financial support by PPARC (research grant PPA/V/S/ 1999/00152) in the form of a visiting fellowship, which was essential to completing the work.

Michel Blanc thanks James Burch and Peter Stauning for their assistance in evaluating this paper.

\section{References}

Ansari, Z. A., The aurorally associated absorption of cosmic noise at College, Alaska, J. Geophys. Res., 69, 4493-4513, 1964.

Arnoldy, R. L., P. B. Lewis, and P. O. Isaacson, Field-aligned auroral electron fluxes, J. Geophys. Res., 79, 4208-4221, 1974.

Bailey, D. K., Some quantitative aspects of electron precipitation in and near the auroral zone, Rev. Geophys., 6, 289-346, 1968.

Baker, D. J., Rayleigh, the unit for light radiance, Appl. Opt., 13, 2160-2163, 1974.

Barcus, J. R., Balloon observations on the relationship of energetic electrons to visual aurora and auroral absorption, J. Geophys. Res., 70, 2135-2147, 1965.

Belon, A. E., G. J. Romick, and M. H. Rees, The energy spectrum of primary auroral electrons determined from auroral luminosity profiles, Planet. Space Sci., 14, 597-615, 1966.

Berkey, F. T., Coordinated measurements of auroral absorption and luminosity using the narrow beam technique, J. Geophys. Res., 73, 319-337, 1968.

Brekke, A., C. Hall, and T. L. Hansen, Auroral ionospheric conductances during disturbed conditions, Ann. Geophys., 7, 269-280, 1989.

Browne, S., J. K. Hargreaves, and B. Honary, An imaging riometer for ionospheric studies, Electron. Commun., 7(5), 209-217, 1995.

Burch, J. L., Diagnostics of auroral acceleration mechanisms by particle measurements, in Auroral Physics, edited by C.-I. Meng, M. J. Rycroft, and L. A. Frank, pp. 97-107, Cambridge Univ. Press, New York, 1991.

Burns, C. J., W. G. Howarth, and J. K. Hargreaves, High-resolution incoherent scatter radar measurements during electron precipitation events, J. Atmos. Terr. Phys., 52, 205-218, 1990.

Campbell, W. H., and H. Leinbach, Ionospheric absorption at times of auroral and magnetic pulsations, J. Geophys. Res., 66, 25-34, 1961.

Collis, P. N., and J. K. Hargreaves, Co-ordinated studies using imaging riometer and incoherent scatter radar, J. Atmos. Terr. Phys., 59, 873-890, 1997.

Collis, P. N., J. K. Hargreaves, and A. Korth, Auroral radio absorption as an indicator of magnetospheric electrons and of conditions in the disturbed auroral D-region, J. Atmos. Terr. Phys., 46, 21-38, 1984.

Collis, P. N., J. K. Hargreaves, and G. P. White, A localised co-rotating auroral absorption event observed near noon using imaging riometer and EISCAT, Ann. Geophys., 14(12), 1305-1316, 1996.

Currie, B. W., Auroral heights over west-central Canada, Can. J. Phys., 33, 773-779, 1955. del Pozo, C. F., J. K. Hargreaves, and A. D. Aylward, Ion composition and effective ion recombination rate in the nighttime auroral lower ionosphere, J. Atmos. Sol. Terr. Phys., 59, 1919-1943, 1997.

del Pozo, C. F., E. Turunen, and T. Ulich, Negative ions in the auroral mesosphere during a PCA event around sunset, Ann. Geophys., 17, 782-793, 1999.

Eather, R. H., and F. Jacka, Auroral absorption of cosmic radio noise, Aust. J. Phys., 19, 215-239, 1966.

Evans, D. S., The observations of a near monoenergic flux of auroral electrons, J. Geophys. Res., 73, 2315-2323, 1968.

Frank, L. A., and K. L. Ackerson, Observations of charged particle precipitation into the auroral zone, J. Geophys. Res., 76, 3612-3643, 1971.

Friedrich, M., and K. M. Torkar, High-latitude plasma densities and their relation to riometer absorption, J. Atmos. Terr. Phys., 45, 127135, 1983.

Gustafsson, G., Ionization in the $D$-region during auroral break-up events, Planet. Space Sci., 12, 195-208, 1964.

Gustafsson, G., Spatial and temporal relations between auroral emission and cosmic noise ansorption, Planet. Space Sci., 17, 1961-1975, 1969.

Hardy, D. A., M. S. Gussenhoven, and E. Holeman, A statistical model of auroral electron precipitation, J. Geophys. Res., 90, 4229-4248, 1985.

Hargreaves, J. K., Auroral absorption of HF radio waves in the ionosphere: A review of results from the first decade of riometry, Proc. IEEE, 57(8), 1348-1373, 1969.

Hargreaves, J. K., and T. Devlin, Morning sector electron precipitation events observed by incoherent scatter radar, J. Atmos. Terr. Phys., 52, 193-203, 1990.

Holt, O., and A. Omholt, Auroral luminosity and absorption of cosmic radio noise, J. Atmos. Terr. Phys., 24, 467-474, 1962.

Ishimoto, M., C.-I. Meng, G. J. Romick, and R. E. Huffman, Auroral electron energy and flux from molecular nitrogen ultraviolet emissions observed by the S3-4 satellite, J. Geophys. Res., 93, 9854-9866, 1988.

Johansen, O. E., Comment on "The aurorally associated absorption of cosmic noise at College, Alaska” by Z. A. Ansari, J. Geophys. Res., 70, 3787-3788, 1965a.

Johansen, O. E., Variations in energy spectrum of auroral electrons detected by simultaneous observation with photometer and riometer, Planet. Space Sci., 13, 225-235, 1965 b.

Kirkwood, S., and A. Osepian, Quantitative studies of energetic particle precipitation using incoherent scatter radar, J. Geomagn. Geoelectr., 47, 783-799, 1995.

Kosch, M. J., T. Hagfors, and E. Nielsen, A new digital all-sky imager experiment for optical auroral studies in conjunction with the Scandinavian twin auroral radar experiment, Rev. Sci. Instrum., 69, 578584, 1998.

Lui, A. T. Y., D. Venkatesan, C. D. Anger, S.-I. Akasofu, W. J. Heikkila, J. D. Winningham, and J. R. Burrows, Simultaneous observations of particle precipitation and auroral emissions by the ISIS 2 satellite in the 19-24 MLT sector, J. Geophys. Res., 82, 2210-2226, 1977.

Lundin, R., Rocket observations of electron spectral and angular characteristics in an "inverted V" event, Planet. Space Sci., 24, 499-514, 1976.

Maynard, N. C., D. S. Evans, B. Maehlum, and A. Egeland, Auroral vector electric field and particle comparisons, 1, Premidnight convection topology, J. Geophys. Res., 82, 2227-2234, 1977.

Mende, S. B., R. H. Eather, M. H. Rees, R. R. Vondrak, and R. M. Robinson, Optical mapping of ionospheric conductance, J. Geophys. Res., 89, 1755-1763, 1984.

Ogilvie, K. W., Auroral electron energy spectra, J. Geophys. Res., 73, 2325-2332, 1968.

Penman, J. M., J. K. Hargreaves, and C. E. McIlwain, The relationship between 10 to $80 \mathrm{keV}$ electron precipitation observed at geosynchronous orbit and auroral radio absorption observed with riometers, Planet. Space Sci., 27, 445-451, 1979.

Rees, M. H., Auroral ionization and excitation by incident energetic electrons, Planet. Space Sci., 11, 1209-1218, 1963.

Rees, M. H., Physics and Chemistry of the Upper Atmosphere, Cambridge Univ. Press, New York, 1989.

Rees, M. H., and D. Luckey, Auroral electron energy derived from ratio of spectroscopic emissions, 1, Model computations, J. Geophys. Res., 79, 5181-5186, 1974. 
Rees, M. H., D. Lummerzheim, R. G. Roble, J. D. Winningham, J. D. Craven, and L. A. Frank, Auroral energy deposition rate, characteristic electron energy, and ionospheric parameters derived from Dynamics Explorer 1 images, J. Geophys. Res., 93, 12,841-12,860, 1988.

Rishbeth, H., and A. P. van Eyken, EISCAT: Early history and the first ten years of operation, J. Atmos. Terr. Phys., 55, 525-542, 1993.

Robinson, R. M., and R. R. Vondrak, Validation of techniques for space based remote sensing of auroral precipitation and its ionospheric effects, Space Sci. Rev., 69, 331-407, 1994.

Sears, R. D., and R. R. Vondrak, Optical emissions and ionization profiles during an intense pulsating aurora, J. Geophys. Res., 86, 6853-6858, 1981.

Spiro, R. W., P. H. Reiff, and L. J. Maher Jr., Precipitating electron energy flux and auroral zone conductances: An empirical model, $J$. Geophys. Res., 87, 8215-8227, 1982.

Stauning, P., High-latitude $D$ - and $E$-region investigations using imaging riometer observations, J. Atmos. Terr. Phys., 58, 765-783, 1996 .

Stauning, P., Investigations of ionospheric radio wave absorption processes using imaging riometer techniques, J. Atmos. Terr. Phys., 58, 753-764, 1996b.

Steele, D. P., and D. J. McEwen, Electron auroral excitation efficiencies and intensity ratios, J. Geophys. Res., 95, 10,321-10,336, 1990.

Stoker, P. H., M. J. Mathews, and M. W. J. Scourfield, Coordinated measurements of auroral light intensities and riometric radio-wave absorption, Geophys. Res. Lett., 23, 641-644, 1996.
Störmer, C., The Polar Aurora, pp. 67-80, Oxford Univ. Press, New York, 1955

Turunen, E., H. Matveinen, and H. Ranta, Sodankylä Ion Chemistry (SIC) model, Rep. 49, Sodankylä Geophys. Obs., Finland, 1992.

Vallance Jones, A., Auroral spectroscopy and thermosphere, in $A u$ roral Physics, edited by C.-I. Meng, M. J. Rycroft, and L. A. Frank, pp. 15-28, Cambridge Univ. Press, New York, 1991.

Vondrak, R. R., and R. D. Sears, Comparison of incoherent scatter radar and photometric measurements of the energy distribution of auroral electrons, J. Geophys. Res., 83, 1665-1667, 1978.

Vondrak, R., S. Harris, and S. Mende, Ground-based observations of subauroral energetic-electron arcs, Geophys. Res. Lett., 10, 557-560, 1983.

Whalen, B. A., and I. B. McDiarmid, Observations of magnetic-fieldaligned auroral-electron precipitation, J. Geophys. Res., 77, 191-202, 1972.

Westerlund, L. H., The auroral electron energy spectrum extended to 45 ev, J. Geophys. Res., 74, 351-354, 1969.

C. F. del Pozo, F. Honary, M. J. Kosch, and S. R. Marple, Department of Communication Systems, Lancaster University, Lancaster LA1 4YR, England, U.K. (m.kosch@lancaster.ac.uk)

T. Hagfors, Max-Planck-Institut für Aeronomie, Max-Planck-Str. 2, 37191 Katlenburg-Lindau, Germany.

(Received December 29, 2000; revised June 11, 2001; accepted June 24, 2001.) 
